Meta

Journal des traducteurs

Translators' Journal

\title{
Towards a Model of Translation Competence
}

\section{Stuart J. Campbell}

Volume 36, numéro 2-3, juin 1991

URI : https://id.erudit.org/iderudit/002190ar

DOI : https://doi.org/10.7202/002190ar

Aller au sommaire du numéro

Éditeur(s)

Les Presses de l'Université de Montréal

ISSN

0026-0452 (imprimé)

1492-1421 (numérique)

Découvrir la revue

Citer cet article

Campbell, S. J. (1991). Towards a Model of Translation Competence. Meta,

Campbell, S. J. (1991). Towards a Model of Translatid
36(2-3), 329-343. https://doi.org/10.7202/002190ar

\section{Résumé de l'article}

On examine les tests de traduction pour déterminer jusqu'à quel point ils évaluent la compétence en traduction et sont révélateurs des processus de traduction plutôt que des comparaisons entre les textes de départ et d'arrivée. On propose un plan d'un modèle de compétence en traduction. Une étude de cas présentant des caractéristiques de compétence en traduction et un schéma d'évolution est proposée. Ce modèle de compétence en traduction est élaboré et accompagné de suggestions pour les tests de traduction et les programmes à l'études. 


\section{TOWARDS A MODEL OF TRANSLATION COMPETENCE}

STUART J. CAMPBELL

University of Western Sydney (Macarthur), Sydney, Australia

RÉSUMÉ

On examine les tests de traduction pour déterminer jusqu'à quel point ils évaluent la compétence en traduction et sont révélateurs des processus de traduction plutôt que des comparaisons entre les textes de départ et d'arrivée. On propose un plan d'un modèle de compétence en traduction. Une étude de cas présentant des caractéristiques de compétence en traduction et un schéma d'évolution est proposée. Ce modèle de compétence en traduction est élaboré et accompagné de suggestions pour les tests de traduction et les programmes d'études.

\section{ABSTRACT}

Translation tests are discussed to determine the extent to which they assess translation competence and reveal translation processes rather than comparisons between source and target texts. An outline of a model of translation competence is suggested, and further developed through a case study, which proposes components of translation competence and a developmental schema. Finally a model of translation competence is proposed, and suggestions are made in the light of the model about translation testing and curriculum design.

\section{DETERMINING TRANSLATION COMPETENCE THROUGH TRANSLATION TESTS}

\section{Introduction}

Given that translation competence is generally held to be assessable by test, and that translation tests are in widespread use for accreditation purposes, the question of translation test characteristics is surprisingly rarely examined given the wealth of research on educational measurement in general and language assessment in particular. Obvious questions that might be posed are: Are translation tests reliable? Are they valid? How effectively do they discriminate among candidates? How can their level of difficulty be determined?

This latter aspect is tackled in this section, where we attempt to determine the extent to which a translation test can be said to comprise items of differing difficulty. Our conclusions lead us to larger questions of translation competence.

Forty one renditions into English of one sentence of an Arabic test passage were analysed. The basic technique was to list and group the various renditions of a) individual lexical items, and b) grammatical structures. For each item the percentage of subjects producing each rendition was calculated, and the renditions ranked. For example, mashaakil was rendered by 38 subjects $(92.68 \%)$ as problems, by one $(2.44 \%)$ as thing, by one as subject, and was omitted by one subject. Finally, the various items were ranked according to their apparent easiness, so that an item where most subjects produced a "correct" translation was easier and one where fewer produced a "correct" translation was more difficult. 


\section{Difficulty-ranking of lexical items}

The items examined included tutabar (glossed as is considered), min (glossed as of), aswa' (worst), mashaakil (problems), yuwaajihuhaa (faces them), biTaala (unemployment), 'aalam (world).

With biTaala, aswa', mashaakil, yuwaajihuhaa and 'aalam, there appear to be easily accessible "standard" translations - unemployment, worst, problems, face and world respectively - that are chosen by between $83 \%$ and $100 \%$ of all subjects. Various kinds of deviations from the norm were observed. In the case of biTaala, one subject gave the unemployed, while another gave the unemployment situation. These two seem to be offering a change of viewpoint: The first focusses on the people involved in unemployment, while the second sets unemployment up as a current issue. For aswa', most of the deviations from the norm were to mistakenly use the comparative worse instead of worst. If these are added to the worst total, only two subjects are left. One used most difficult and the other omitted the item. With mashaakil deviations from problems were thing as a kind of proform (the unemployment situation is the worst thing facing ...) and subject. The verb yuwaajihuhaa was rendered as face by all but three subjects. One produced confront and two omitted the item.

Two items showed much less agreement among subjects: For tu'tabar $65.85 \%$ gave consider, $12.2 \%$ gave regard and $2.44 \%$ offered recognize. The remaining $17.07 \%$ rendered the item as is. The preposition min was translated as one of by $65.85 \%$ of the candidates and left untranslated by the remainder.

To summarize, individual lexical items can be ranked according to their "difficulty" if difficulty is defined as the extent to which subjects fail to agree on a rendition of the item. For example, in a hypothetical passage "the cat died of an intriguing ailment" we would expect there to be universal agreement on the translation of "cat", but much less agreement on the translation of "an intriguing ailment"; the latter is clearly more difficult. For the items examined here, the ranking is as follows:

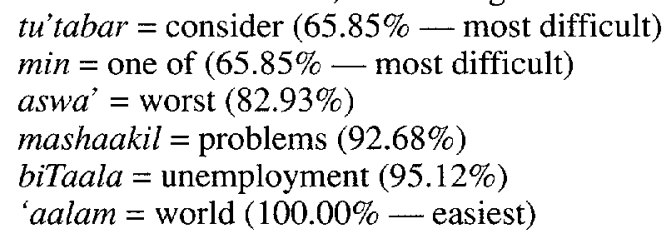

\section{Difficulty-ranking of grammatical structures}

Here defining the item is the first difficulty since, unlike words, grammatical structures do not always have obvious boundaries; drawing the line around a piece of grammatical structure depends on where we arbitrarily choose to stop at a constituent boundary. For example the string [which [seemed [[to [develop]] unnoticed]]] contains at least four boundaries. Our choice of three pieces of structure were made intuitively. The items were: A passive verb and its subject (but not its complement); tu'tabar al-biTaala (glossed as unemployment is considered): A prepositional phrase containing an adjective in the elative form; min aswa' al-mashaakil (glossed as one of the worst problems): A relative clause; allatii yuwaajihuhaa al-'aalam (glossed as which the world faces).

The passive verb produced several versions: A noun subject and passive verb (unemployment is considered) was the most frequent, produced by $73.17 \%$ of the subjects. The next most frequent, with $17.07 \%$ of subjects was a simple copula clause unemployment is. The third was a pseudocleft on the model of it is considered that unemployment, offered by $7.32 \%$ of subjects. Last was a single subject who used an active verb with a verbal complement unemployment seems to be. 
$65.85 \%$ of the subjects produced one of the + superlative adjective + problems for min aswa' al-mashaakil. A large minority - 31.71\% - produced the + superlative adjective + problems, missing out the beginning of the string, while one subject omitted all but the noun.

With the relative clause, a range of versions was offered including: A reduced relative clause with active verb and incorrect actor (facing the world; 36.59\%); a reduced relative clause with active verb and correct actor (the world faces; $24.39 \%$ ); a full relative clause with incorrect actor (which face the world; $12.20 \%$ ); a reduced relative clause with passive verb and correct actor (faced by the world; $9.76 \%$ ); various garbled attempts $(9.76 \%)$ and a full relative clause with active verb and correct actor (which the world faces; $7.32 \%$ ).

To summarize, the three pieces of structure can be ranked as follows: difficult) allatii yuwaajihuhaa al-'aalam = relative clause with correct actor $(41.47 \%$; most min aswa' al-mashaakil $=$ one of the + superlative adjective + problems $(65.85 \%)$ tu'tabar al-biTaala $=$ unemployment + passive verb $(73.17 \%$; easiest $)$

\section{The utility of item difficulty analysis}

Analysing the difficulty of items in translation is clearly quite different from analysing multiple choice test items, where item difficulty analysis is a standard procedure. The most obvious problem is that of determining what is correct and what is incorrect. While we have accepted majority opinion on lexical items - 'aalam is used by all subjects for world - we have rejected the norm established by our subjects and claimed that world is the correct actor in the relative clause. Another problem was in defining the boundaries of an item as we saw in the grammatical structures. Furthermore, the variety of renditions of grammatical structures forces us to make decisions about the level of delicacy with which we deal with correctness; our criterion for correctness with the relative clause was the choice of actor, but this ignored questions of the aspect of the target language verb and whether the relative clause was full or reduced.

A tentative view of item difficulty analysis is that at the lexical level it must have some utility for translation testing. Test writers ought to be able to establish norms after experience with a test so that lexical items are weighted according to the probability of a candidate producing the "right" rendition. In grammar, similar norms may be able to be established for some structures. However, these norms are more likely to deal with outright errors such as omissions. Such a norm might be stated as follows: "Weight heavily an item where component $x$ is frequently omitted, and weight lightly an item where component $y$ is seldom omitted". Despite these difficulties, test writers surely cannot ignore relativities among items and must attempt to weight items according to established norms. To return to the matter of correctness, it would clearly be more fruitful to try to see behind apparent errors and characterize the processes that give rise to them. Many researchers in translation studies are currently concerned with the importance of the process of translation rather than the product. Toury (1984) has pointed to the langue rather than parole orientation of translation theory and called for an understanding of translation that recognizes the innate abilities of the "native translator". His notion of individual characteristics is borne out by the work of Krings (1987), who shows through think-aloud protocols that "idiosyncratic translation problems" are common. Neubert (1984) suggests a teaching methodology that tries to directly access the processes of translation through retrospective discussion. A cognitive model that includes declarative and proceduralized processes is explored by Dechert (1987), while Hlebec (1989) presents a theory of translation that embraces a range of cognitive and attitudinal phenomena. While the think- 
aloud protocol is currently an important tool in detecting these processes, there is no reason why product data such as tests cannot be fruitfully used. The following section attempts to lay some of the groundwork.

\section{CHARACTERIZING TRANSLATION PROCESSES \\ Product phenomena}

The phenomena observed in our attempt to grade item difficulty can be roughly described and categorized from a product viewpoint using much the same paradigm as, say, the trajectional analysis of Malone (1986) where source and target items are compared equivalence, although one obvious difference is that our orientation is towards translation into the second language so that we have to incorporate phenomena that have to do with mishandling of the mechanics of the target language. The classification of product phenomena below is somewhat ad hoc; its main feature is that it tries to exclude the human agency, except for the role of the judge of equivalence:

- Standard translation: The semantically or grammatically closest target language equivalent to a source language word or structure, eg. unemployment for biTaala, passive for tu'tabar.

- Change of focus: A semantically close equivalent, but one that involves a shift of viewpoint on the part of the reader, eg. the unemployment situation for biTaala, is rather than is considered for tu'tabar (although this latter example could also be classified as omission).

- Grammatical inaccuracy: A target language item that does not convey the semantic relationship expressed by the source language item, eg. worse for aswa', incorrect actor in allatii yuwaajihuhaa.

- Omission: The lack of any target language item corresponding to a source language item.

- Acceptable alternative: A target language item that is semantically close to the standard translation, and that does not seriously distort the meaning of the source language item, eg. most difficult for aswa', recognize for tu'tabar.

- Grammatical shift: A target language item that is semantically accurate but grammatically different from the source language item, eg. thing for biTaala, reduced relative clause for allatii yuwaajihuhaa.

- Barely acceptable alternative: A target language item that partly conveys the meaning of the source language term, but that is barely acceptable, eg. subject for mashaakil, pseudocleft instead of passive for tu'tabar.

This kind of categorisation has obvious problems. Firstly, many of the phenomena can fall under several categories, eg. omission and change of focus, or acceptable alternative and shift. Secondly, the standpoint of the descriptions vary from one to the other. Some, such as shift, are structural linguistic observations. Others are impressionistic observations; standard translations shade through acceptable alternatives to barely acceptable alternatives in a very woolly fashion. To summarize, the descriptions and categories are very much to do with the product of the translator's efforts and say little about the processes behind them.

\section{Processes underlying product errors}

We now attempt to reclassify our product descriptions from a process viewpoint:

- Standard translation: In process terms, this can be defined as knowledge of and application of the most accepted equivalent.

- Change of focus: A number of processes can be hypothesized here: Miscomprehension of the source language item or deficient target language repertoire 
may force an equivalent that is out of focus; or a matching failure may occur, where the subject knows the standard translation but mismatches - for example, pseudocleft instead of passive. Here, instead of interpreting the Arabic passive in tu'tabar as a grammatical device that allows the patient (in the absence of an actor) to appear in the subject slot, they see it has having something to do with the theme/rheme distinction so that unemployment is forced out of theme position further into the body of the sentence by the pseudocleft opening it is...

Grammatical inaccuracies like worse for aswa' and the "incorrect" actor in allatii yuwaajihuhaa may be attributable to a number of processes. The worse case may be due to poor SL comprehension skills or poor TL production skills; or it may be due to simple processing errors as the subject works under speed. The "incorrect" actor is more interesting since we cannot place the blame on poor comprehension or production skills. Subjects whose SL and TL skills are good enough for them to make a fair job of an English relative clause still make the "wrong" choice. The issue here is that the verb yuwaajihu is reciprocal; problems face the world and the world faces problems. Given this, other factors than the overt marking of "correct" subject on the verb may influence the choice of actor, such as some notion of information flow on the part of the translator. Much more likely, though, is the word order in the Arabic clause; the verb is followed by an enclitic object pronoun and then by the actor, approximately which faces-it the world. It is not difficult to see how the English word order which faces the world works through to the translation. What seems to be happening is that these subjects are reading the semantics rather than the syntax of the original, and are indeed making a processing error. Less clear is the use of progressive rather than nonprogressive aspect in the verb is facing and faces. This classic problem of overlap arises because Arabic makes present tense progressive/nonprogressive distinctions only with difficulty, and not through the verb morphology. Grammatical inaccuracy seems an inappropriate judgement here, and none of the three suggested underlying processes fits.

amissions: In process terms, these may be due to processing errors - a subject simply leaves something out in a hurry - or more fundamental factors such as deficient SL comprehension skills or TL production skills. Either of these may lead to omission being used as an evasion strategy where the item is just too hard. But what of a subject who is quite able to manage the item, is otherwise careful about processing, but still omits an item? Other work in this study suggests that translators' behaviour falls along the two axes of prudent-risk taking and persistent-capitulating. At the risk-taking end of the first axis, omission may be part of the individual translator's disposition; translation assessors are familiar with subjects who habitually leave out complete chunks in otherwise good translations. While we are not confident that disposition fits easily into the category of process, we mention it as a dimension of translation competence that is discussed later in this paper; we will argue that disposition is one of the components of translation competence that dictate translation processes, which in turn dictate translation product.

Acceptable alternative in process terms has to do with choice - for example, recognize instead of consider for tu'tabar. In some cases the choice will be forced because of a subject's deficient TL repertoire. But what of the case where the subject's competence in the TL makes it unlikely that they would not know the "standard" translation? Here we must again have recourse to the notion of disposition and suggest that the subject's general orientation to translation makes marked choices more likely - perhaps a risk taker for whom a little decorative variety is preferable to the safe rendition. Another 
possibility is a matching failure: Let us assume that for a great stock of SL words, regardless of how the bilingual lexicon is represented or stored, there are conventional TL matches; dog for kalb, unemployment for biTaala, and so on. It would seem quite likely that a kind of processing error exists that causes a wrong or off-key match to be made occasionally. Given that a respectable literature exists on slip-of-the-tongue errors in first language processing (see Fromkin 1973 for example), there is no reason to assume that translators are not afflicted with something similar.

The difference between an acceptable alternative and a barely acceptable alternative in process terms is simply one of subjective judgement. One of our examples of the latter was the subject who produced problems throughout the world for problems which the world faces. A number of processes are suggested: An evasion strategy to cover an inability to produce the English relative clause; a risk-taking disposition that produces a "near enough" translation; but not a matching failure - a grammatical mismatch might be more likely in the case of the pseudocleft for passive. To summarize, we have tried to look behind the product of translators and describe the processes that give rise to it, and posited a number of such processes: Knowledge and application of most accepted equivalent; miscomprehension of source language item; deficient target language repertoire; matching failure; processing error; evasion strategy. In addition, it has been suggested that there is a fundamental dimension of disposition that influences the quality of choice-making. At this point we leave this rather loose bundle of notions, but will return to some of them later in order to draw together a model of translation competence. The next section takes a closer look at the product of translation through a case study of aspiring Arabic-English translators.

\section{PROFILING TRANSLATORS ON INDIVIDUAL TRAITS \\ Background to the case study}

The test papers of 38 candidates for a public examination in English-Arabic translation were analysed to determine the type of information that such tests can provide on translation competence. Each candidate translated the same passage of approximately 130 words from Arabic to English. All subjects were non-native speakers of English. The methodology of the case study is not extensively described here, although the author is happy to correspond on the matter. The analyses made on the texts were:

Lexical variety ratio (LVR)

Tokens misspelt (TM)

Average word length (AWL)

Mean lexical agreement (MLA) (See Appendix)

Words directly translated (WD)

Words shifted (WS)

Words omitted (WO)

More verbal (MV)

Content/function words (CF) petence.

The data from these analyses suggested two ways to examine translation com-

First, a correlation matrix was built to check whether there were discrete factors indicated by bunching of correlation coefficients. It was reasoned that since there was no global performance measure in the correlation matrix, such factors, or components, of competence might apply across the ability range. To establish this would be important if it could be shown that at least some aspects of translation competence were independent of language competence. 
Second, the global marking scheme used by the accrediting authority that supplied the texts was used to break the candidates into four ability groups. Mean scores on each analysis were plotted for each group to determine whether a developmental schema for translation competence could be suggested.

\section{Translation competence components}

The correlation matrix for the 38 subjects and ten analyses displays bunching that suggests three factors. These are tentatively called lexical coding of meaning, global target language competence and lexical transfer competence.

The lexical coding of meaning component is suggested by the bunching of text length, lexical variety, average word length, words directly translated and content/ function words:

$\begin{array}{lrrrr} & \text { LVR } & \text { AWL } & \text { WD } & \text { CF } \\ \text { TL } & -.65 & -.42 & .32 & -.63 \\ \text { LVR } & & .39 & .37 & .46 \\ \text { AWL } & & -.26 & .61 & \\ \text { WD } & & & & .20\end{array}$

This subset of the correlation matrix shows that short target texts accompany varied vocabulary, longer words, more content words and less direct translation. Conversely, long target texts are accompanied by less varied vocabulary, shorter words, less content words and more direct translation. The clear suggestion is that there is a spectrum of ability from coding meaning lexically to coding meaning grammatically. At the lexical end of the spectrum, translators produce concise, dense text; at the grammatical end they produce strung-out, loose text. The subjects U59 and U84 in the examples below scored respectively as follows: TL 134,181; LVR .72,.60; AWL 5.20,4.97; WD 50,85; CF .94, .88.

\section{Subject: U59}

... although many until recently had believed that some countries have no unemployed, either because these countries were rich or because of the economic policies which they pursue.

Subject: U84 (and omissions restored)

... this despit the belief of a lot of people till recent time, that it would (be) impossible to find unemployed in some countries either due to the (illegible) enjoyed by those countries or as a result of thier economic processes and system followed by those countries.

The two translations quite clearly show a difference in the ability to code meaning lexically; the question arises as to whether that difference is due to differences in target language competence. From a structural point of view, each subject has good control over English syntax, and it would need a comprehensive separate measure to show that one was greatly more proficient than the other. The same goes for control over English style; the more bureaucratic style of U59 may be due to his/her control over English style per se (although a separate test would need to confirm this) or to his/her ability as a translator. Given that the subset of the correlation matrix shown above covers the whole ability range among the subjects, which included some examples of grim English competence, the question is certainly not closed. Indeed the next set of examples suggest that at the "grammatical" end of the spectrum can be found subjects with quite poor (U81) and quite 
good (U77) English, and that even a subject with poor English like U54 can be put near the "lexical" end of the spectrum:

\section{Subject: U81}

... in spite of a lot of people belief up to recent time that some countries have not get unemployed people either because of these countries affluency or the economical system which these countries follow.

Subject: U77

... despite the belief of many, until recently, that it is not possible to find unemployed people in some countries either because of the wealth that those countries enjoy or as a result of the economic strategies that they follow.

\section{Subject: U54}

... the majority thinks not long ago that some countries don't have any people without a job, because of the resources and wealth and the economy structure.

Target language competence is indicated by the bunching of tokens misspelt, words shifted, words omitted and more verbal:

$\begin{array}{lrrr} & \text { WS } & \text { WO } & \text { MV } \\ \text { TM } & -.39 & .36 & -.38 \\ \text { WS } & & .01 & .41 \\ \text { WO } & & & -.28\end{array}$

Mispellings are accompanied by few shifts, more omissions and more verbal style. Good spelling accompanies more shifts, few omissions and a more verbal style. Subjects U75 and U68 exemplify the poor and good ends of the scale:

\section{Subject: U75}

... insight off so many thought in near future few countries won't have the unemployed workers, the reason is the countries fianancial cercumstances or local industrial.

\section{Subject: U68}

... this is despite the believe held by many people until recently that some states can not have unemployed people, either because of the wealth enjoyed by those states, or as a result of the economical regimes they adopt.

The logic behind the bunching is fairly transparent. Ability to spell needs no comment. Omissions indicate gaps in comprehension of the original or in the productive repertoire. The ability to shift and the use of more verbal style indicate subjects' ability to break out of the syntactic mould of the source language (which is characteristically highly nominal).

The third component proposed from the correlation matrix is lexical transfer competence, suggested by the bunching of mean lexical agreement, words shifted and words directly translated:

$\begin{array}{lrr} & \text { WS } & \text { WD } \\ \text { MLA } & .46 & -.62 \\ \text { WS } & & -.72\end{array}$


Here, high peer agreement on lexical transfers accompanies more shifts and less direct translations; low peer agreement on lexical transfers is accompanied by less shifts and more direct translations. The relationship between shifts and direct translations is almost a mechanical one, so that what this bunching says in simple terms is that standard translations tend to be managed in subjects who can manipulate the syntactic space between source and target language. This suggests that lexical transfer competence is closely linked to global language competence per se, or at least to a greater extent than is lexical coding of meaning. In the examples below, U53 is largely in agreement with his/ her peers on lexical transfers, while U51 is rather idiosyncratic:

\section{Subject: U51}

... in spite of the many believe until short time ago that, some countries do not have unemployed people eithe, because of the affluence they enjoy these countries or the result of the economic plans which they create.

Subject: U53

... in spite of the opinion by many up till recently, that some nations did not have unemployed: because of either the wealth of these nations or their economic structure and policy.

To conclude this section, let us summarize: The correlation matrix suggested three components of translation competence. The first, lexical coding of meaning, may be to an extent independent of global target language competence so that subjects with good English skills may vary in their ability to produce dense, lexical text, and even some subjects with poor English may have some notion of textual density. The second component, global target language competence, can be assumed to correlate with global target language competence measured in other ways. The third component is lexical transfer competence, and is likely to be closely linked to global target language competence.

\section{A tentative developmental schema for translation competence}

Each translation was assigned a score based on the marking scheme of the accrediting organisation that supplied them. The marking scheme yields a score out of 50 and works on a deductive principle; the candidate begins with 50 marks, and error marks are deducted. The papers were marked by the author who, as an official marker, is experienced in using the system. The subjects were then divided into four groups, namely $0 / 50$ $3.5 / 50,14.5 / 50-25 / 50,27.5 / 50-35 / 50,38 / 50-44.5 / 50$. All scores on the ten analyses were standardized (converted to T-scores), and then summed and averaged for each of the four groups. This enabled a "developmental" plot to be made for each analysis.

The analyses fell into two types: Half had a developmental plot that either fell or rose; half had a more or less bell-shaped curve. In the first type it can be said that the feature measured steadily improved or deteriorated; in the second it began at a certain level, then improved or deteriorated, and finally returned to near where it began. The two types are discussed in detail below:

- Words omitted: These lessened sharply between the poorest and second poorest group. In the top three of the four groups omissions were of a similar degree. This feature is doubtless related primarily to source and/or target competence, although it seems that even mediocre subjects are able to work around potential omissions.

- Lexical variety: This was low and little distinguished in the bottom three of the four groups, but sharply increased between the second highest and the highest group. 
- Tokens misspelt: Mispellings sharply decreased between the lowest and the second lowest groups, remained in the middle range in the two middle groups, and then sharply decreased in the top group.

- Mean lexical agreement: Agreement with peers on lexical transfers improved steadily and then flattened out in the two top groups.

- Words shifted: This remained low in the two lowest groups, then rose sharply in the two top groups.

- Average word length: Word length was relatively high in the lowest group, then fell in the second lowest group before rising steadily in the second highest and the highest groups. The high figure in poor subjects is almost certainly explained by telegraphic text with few function words. The middle groups have a high proportion of function words, and therefore shorter average words; the highest group has more content words.

- Words directly translated: These begin low in the lowest group, rise in the second lowest group, then fall steadily to the highest group. The explanation is likely to be that the poorest subjects lack the repertoire even to make a reasonable number of direct translations. The next group has the repertoire, but unlike the higher groups does not have the skills to avoid overuse of direct translation by using shifts.

- Content/function words: The lowest group begins with high content words; there follows a sharp increase in function words and then an increase in content words in the two highest groups. This pattern is very similar to that for average word length.

- Text length: Text length is short in the lowest group, high in the two middle groups, and low in the highest group. This pattern is similar to that for average word length and content/function words: Poor subjects produce telegraphic "grammarless" text; mediocre subjects code meaning grammatically and take many words to do it; good subjects compress their text by coding meaning lexically.

- More verbal: Poor subjects produce very nominal text - again telegraphic while there is a sharp increase in verbal style in the second lowest group, followed by a steady return to more nominal style in the two highest groups. The sharp increase in verbal style in the mediocre groups is almost certainly due to their breaking the threshhold of target language competence; in the highest groups, control over lexical coding of meaning may counteract the verbalising tendency.

It remains to propose a crude implicational hierarchy derived from the "developmental" plots, based on threshholds evident in the plots. The hierarchy comprises three stages, based on the three highest of the four groups:

\section{Stage 1:}

Substantial decrease in omissions

\section{Stage 2:}

Increase in word length

Agreement with peers on lexical transfers

Decrease in direct translations

Increase in shifts

Increase in content words

More nominal style 
Stage 3:

Decrease in text length

Increase in variety of vocabulary

Accurate spelling

To conclude this section and this discussion of the case study, it certainly appears that there is a developmental dimension to translation competence, albeit one derived from cross-sectional data. The developmental schema begins with poor language skills producing telegraphic translations with many omissions; beyond the first threshhold, translations are still telegraphic but have few omissions; beyond the second, subjects have control of target language structures and lexical transfers; beyond the final threshhold they are able to compress text, spell accurately and vary vocabulary.

\section{A TENTATIVE MODEL OF TRANSLATION COMPETENCE Overview}

In this section, we try to draw together the threads of our discussion to put forward a tentative model of translation competence. We then suggest the outline of a method for assessing competence, and finally make some comments on translation curriculum in the light of our proposals on translation curriculum.

\section{Translation competence}

The model comprises two basic parts: Disposition and proficiency.

Disposition has to do with attitudes and psychological qualities that the translator brings to the task; we have proposed that there are the two axes of risk-taking vs prudent and persistent vs capitulating; it is certain that these could be refined further. The translator's disposition is independent of proficiency so that even a person with well developed proficiency may produce quite different translations from another with a different disposition. Proficiency has to do with certain special bilingual skills, and has a developmental dimension. We propose that there are three aspects to proficiency: lexical coding of meaning; global target language competence; lexical transfer. These three aspects are closely related to one another, although lexical coding of meaning may be somewhat independent of the other two. The individual skills that make up these aspects of proficiency tend to develop by way of threshholds and are implicationally arranged.

\section{Assessing translation competence}

As we saw in Section 1, the traditional test of translation - direct testing - is amenable to item difficulty analysis, so that in theory, translation texts could be written or weighted to focus on particular aspects of competence. However, such an exercise would need to be based on a decision as to whether processes can be effectively assessed, or whether the assessor was happy to measure only the product. An assessment procedure to measure the former would have to be far more sophisticated than one that merely marked microlinguistics features. Linked to this question is the purpose of testing.

A test that aimed to simply assess translation competence once at a given moment could honestly operate by means of microlinguistic marking, as long as it were based on norms of item difficulty and did not hope to randomly assess competence with a text chosen with not much more than an arbitrary judgement as to its overall difficulty. Even so, one suspects that much more reliable testing could be achieved by the use of a number of short purpose-written passages, each focussing on certain microlinguistic features. A more stringently reductionist view would suggest that much of the desired data could be elicited by separate tests of source and target language competence. 
A diagnostic test for the potential to develop translation competence (such as an entrance test for a translation course) must look at process and the developmental dimension. It would need to answer these questions: Firstly, can purely linguistic competence in source and target languages be separated from dispositional aspects of the candidate's test performance? And if so, to what extent is disposition amenable to instruction? Secondly, where does the candidate stand in the developmental process towards becoming a translator? And does the candidate's developmental stage preclude his/her attaining translation competence given reasonable time and available instruction?

\section{Curriculum implications}

A breakdown of competence components is a sine qua non of curriculum writing. Our analysis suggests that the curriculum should involve the following: Diagnosis of language competence and the construction of a syllabus that reflects the developmental path; and diagnosis of disposition, which informs a syllabus designed to teach pragmatic matters of judgement and extralinguisic aspects of translation practice. The stopgap curriculum model developed and implemented in the author's university goes some way to meeting these specifications with its two major dimensions of skill objectives (to develop microlinguistic translation skills) and task objectives (to develop pragmatic skills for dealing with specific text types). However the model at present lacks an effective diagnostic component.

\section{Appendix}

Mean Lexical Agreement (MLA): This analysis was intended to measure the extent to which each subject translated words "correctly". The clear problem (expressed in hoary translators' anecdotes about dozens of perfectly correct but different renditions) is the difficulty of finding norms. For example, the fragment yandur wujuud balad may be translated variously as it is rare to find a country, a country hardly exists, and so on. The verb yandur connotes find and exist, and in any case demands an obligatory grammatical shift from (literally) is-rare existencelfinding country.

What sources might there be? The overarching source of norms is the body of knowledge held by bilinguals; but how to access it? Three ways seem to present themselves. Firstly, and naively, bilingual dictionaries are supposed to represent bilingual knowledge. But the problems of comprehensiveness, currency and context make this a poor choice. Secondly, a sample of "perfect" bilinguals might be asked to judge the correctness of a particular transfer. Again, serious problems arise; "perfect" bilinguals may exist, but one would be hard pressed to unequivocally identify them. The third method is to derive the norms of lexical transfer from the population being tested, in other words to calculate the extent to which each subject agrees with the other subjects on the translation of particular items. The method works as follows:

For each of the twenty sample source language text items, the different renditions of each subject were collated. In the case of biTala, for example, almost all the subjects produced unemployment, and this could be safely considered the norm. But with wujuud, the case was less clear. Of the 38 subjects, 24 used find in some configuration (to find, finding, etc.), seven used there is, three used exist, while two produced see and have. Two subjects missed the item altogether. Here find is apparently the norm, but is not favoured as strongly as unemployment for biTala. If our task here is to assess the accuracy of transfer (although see below), then it is necessary to weight more heavily those source language items that have higher normative strength. In other words, a translator who cannot render unemployment for biTala is much more out of kilter than one who cannot render find for wujuud. 
Normative strength is easily weighted by calculating the standard deviation of the frequency of occurrence of the various renditions. For example:

$\begin{array}{llr}\text { ITEM } & \text { VERSION } & \mathrm{n} \\ \text { wujuud } & \text { find } & 24 \\ & \text { there is } & 7 \\ & \text { exist } & 3 \\ & \text { see } & 1 \\ & \text { have } & 1\end{array}$

normative strength $=$ standard deviation $=2.83$

$\begin{array}{llr}\text { ITEM } & \text { VERSION } & \mathrm{n} \\ \text { yuwaajihu } & \text { face } & 35 \\ & \text { confront } & 1\end{array}$

normative strength $=$ standard deviation $=24.04$

Where all subjects agree on a single rendition, an artificial standard deviation is calculated by the use of a dummy 1 alongside the number of occurrences of the single rendition.

The final step is to average the deviation scores for each subject to give mean weighted lexical transfer agreement.

Two interesting points emerge: Firstly, our aim of measuring "correctness" or "accuracy" of transfer is not achievable; we can only measure the extent to which subjects agree. The nature of disagreement is a rich vein to be mined. At the one extreme is the hopeless case where the subject makes a stab at translation through misunderstanding the source language item or not having a target language equivalent in his/her repertoire. At the other end is the linguistic sophisticate who can produce quirky renditions such as joblessness or idleness for biTala. Note that a subject who renders being out of work is classified as having shifted and the item is not counted in his/her Mean Lexical Agreement score.

The second point is whether the norms so produced can be objectively incorrect. At the lexical level, this could only occur because of an extraordinary conspiracy of ignorance - say, all subjects translated dog as cat. At a higher level of structure, though, it seems that norms can be objectively wrong. An example mentioned earlier in this paper is that of the reciprocal verb yuwaajih. The verb occurred in the context of (translated) problems which the world faces. Many subjects had difficulty in transferring the actor/ patient relationship as it occurred in the SL text; only $41.46 \%$ had world as actor, while $48.78 \%$ had problems as actor, ie. problems which face the world. The norm, although it barely scrapes in as such, accepts actor and patient coded contrary to the SL text.

To summarize, Mean Lexical Agreement is a fairly robust but indirect measure of accuracy of transfer, although it less robustly measures inaccuracy of transfer in a subject with sophisticated but quirky lexical choices. 


\section{BIBLIOGRAPHY}

DECHERT, Hans W. (1987): "Analysing Language Processing Through Verbal Protocols", C. Faerch \& G. Kasper (Eds.), Introspection in Second Language Research, Clevedon \& Philadelphia, Multilingual Matters, pp. 96-112.

FROMKIN, Victoria A. (Ed.)(1973): Speech Errors as Linguistic Evidence, The Hague, Mouton.

HLEBEC, Boris (1989): "Factors and Steps in Translating", Babel, 35-3, pp. 129-141.

KRINGS, Hans P. (1987): "The Use of Introspective Data in Translation", C. Faerch \& G. Kasper (Eds.), Introspection in Second Language Research, Clevedon \& Philadelphia, Multilingual Matters, pp. 157-176.

MALONE, Joseph L. (1988): The science of Linguistics in the Art of Translation: Some Tools from Linguistics for the Analysis and Practice of Translation, Albany, State University of New York, [Located at Sydney Uni $418.0259]$.

NEUBERT, Albrecht (1984): "Text-bound Translation Teaching", Wolfram Wilss \& Gisela Thome (Eds.), Translation Theory and its Implementation in the Teaching of Translating and Interpreting, Tübingen, Gunter Narr, pp. 61-70.

TOURY, Gideon (1984): "The Notion of 'Native Translator' and Translation Teaching", Wolfram Wilss and Gisela Thome (Eds.), Translation Theory and its Implementation in the Teaching of Translating and Interpreting, Tübingen, Gunter Narr, pp. 186-195.

\section{Appendix 1}

\begin{tabular}{|c|c|c|c|c|c|c|c|c|c|}
\hline & LVR & TM & AWL & MLA & WD & WS & WO & MV & $\mathrm{CF}$ \\
\hline TL & $\begin{array}{l}.65 \\
\text { vhi }\end{array}$ & .00 & $\begin{array}{l}.42 \\
\text { hi }\end{array}$ & .04 & $\begin{array}{l}.32 \\
\text { vlo }\end{array}$ & .14 & $\begin{array}{l}.46 \\
\mathrm{hi}\end{array}$ & .10 & $\begin{array}{l}.63 \\
\text { vhi }\end{array}$ \\
\hline LVR & & .05 & $\begin{array}{l}.39 \\
\text { lo }\end{array}$ & .01 & $\begin{array}{l}.37 \\
\text { vlo }\end{array}$ & .28 & .18 & .00 & $\begin{array}{l}\mathbf{4 6} \\
\text { hi }\end{array}$ \\
\hline $\mathrm{TM}$ & & & .00 & .09 & .09 & $\begin{array}{l}.39 \\
10\end{array}$ & $\begin{array}{l}.36 \\
\text { vlo }\end{array}$ & $\begin{array}{l}.38 \\
\text { vlo }\end{array}$ & .08 \\
\hline AWL & & & & .14 & .26 & .01 & .13 & .11 & $\begin{array}{l}.61 \\
\text { vhi }\end{array}$ \\
\hline MLA & & & & & $\begin{array}{l}.62 \\
\text { vhi }\end{array}$ & $\begin{array}{l}.46 \\
\mathrm{hi}\end{array}$ & .16 & .13 & .21 \\
\hline WD & & & & & & $\begin{array}{l}.72 \\
\text { vhi }\end{array}$ & .31 & .15 & .07 \\
\hline WS & & & & & & & .01 & $\begin{array}{l}. \mathbf{4 1} \\
\text { lo }\end{array}$ & .02 \\
\hline Wo & & & & & & & & .28 & .20 \\
\hline MV & & & & & & & & & .01 \\
\hline
\end{tabular}

Notes on reading the correlation matrix:

Negative correlations are shown in italics; correlations significant at at least .05 are shown in bold.

Significant correlations are further indicated by these notations:

vlo indicates $\mathrm{p}=<.05$

lo indicates $\mathrm{p}=<.02$

hi indicates $\mathrm{p}=<.01$

vhi indicates $\mathrm{p}=<.001$ 


\section{Appendix 2}

Vertical axis represents mean standardised scores.

Horizontal axix represents global scores based on accrediting organisation's scheme.

\section{Text Length}

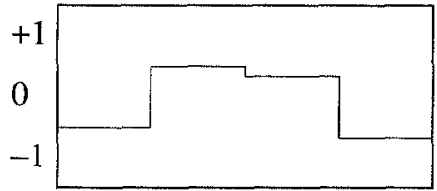

$0-3.5$ 14.5-25 27.5-35 38+

\section{Tokens Misspelt}

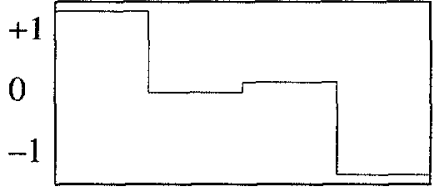

$0-3.514 .5-2527.5-3538+$

Mean Lexical Agreement

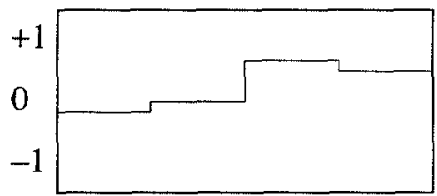

$0-3.514 .5-2527.5-3538+$

Words Shifted

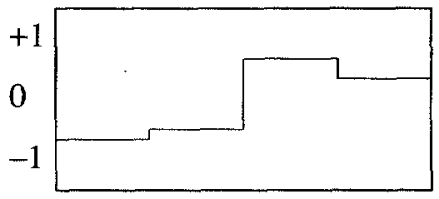

$0-3.514 .5-2527.5-3538+$

More Verbal

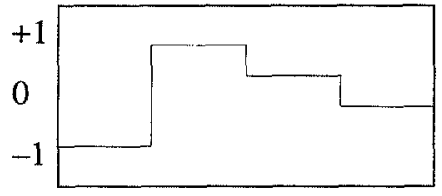

$0-3.514 .5-2527.5-3538+$
Lexical Variety Ratio

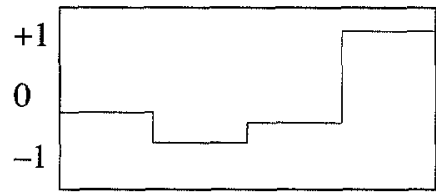

0-3.5 14.5-25 27.5-35 38+

Average Word Length

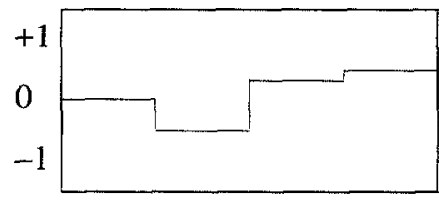

0-3.5 14.5-25 27.5-35 38+

Words Directly Translated

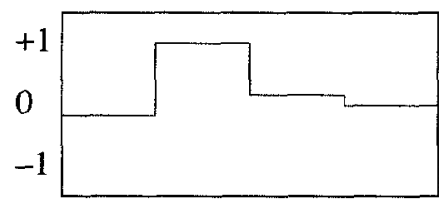

$0-3.5$ 14.5-25 27.5-35 38+

Words Omitted

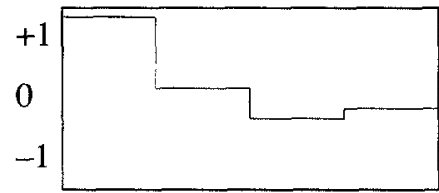

0-3.5 14.5-25 27.5-35 38+

Content/Function Words

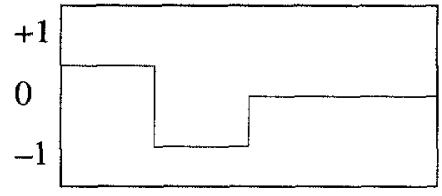

0-3.5 14.5-25 27.5-35 38+ 